\title{
Undue influence, consent and medical treatment
}

\author{
Cameron Stewart LLB PhD Andrew Lynch LLB LLM ${ }^{1}$
}

J R Soc Med 2003;96:598-601

In certain instances the law recognizes that a person's free will may be so influenced by another that agreements made by that person should be set aside. The primary philosophical basis for this doctrine of 'undue influence' is respect for individual autonomy and the need to ensure that people have freely chosen a course of action, before the law will make that course of action binding upon them. In the past, the doctrine of undue influence was confined to situations involving the transfer of property (such as gifts, wills or purchases). But the doctrine is also relevant to consents to medical treatment, most commonly in cases where a patient refuses treatment because of the influence of family members. The purpose of this article is to provide a general outline of the legal concept of undue influence and then to consider its recent application in medical lawsuits.

\section{RELATIONSHIPS OF UNDUE INFLUENCE}

Traditionally, there are three ways in which a court may find that a transaction is tainted by the undue influence of one party over another. ${ }^{1}$ In particular types of relationships, undue influence is automatically presumed and the onus is immediately cast upon the party perceived to be stronger to show that they did not abuse their position. Such relationships include those between solicitors and clients, religious leaders and followers, and parents and children. These categories have been settled upon as displaying two characteristics - (a) obvious power imbalances simply by virtue of the relationship itself; and $(b)$ the unlikelihood that the weaker party would freely confer a benefit by means of gift or contract on the stronger. As a result of this classification, any transaction by which a benefit flows from the patient to a person involved in their medical care (beyond the standard payment for medical services) is automatically presumed to have been secured through improper pressure, even if a reciprocal benefit is transferred.

In other cases, the weaker party must first demonstrate that he or she was in a relationship that was strongly influential in order for a presumption to arise-but, once the court is satisfied that the parties were in such a

Division of Law, Macquarie University and ${ }^{1}$ Faculty of Law, University of Technology Sydney, NSW, Australia

Correspondence to: Dr Cameron Stewart, Senior Lecturer in Law, Macquarie University, NSW, Australia 2109 relationship, the onus is again upon the stronger party to rebut the presumption that the influence was undue.

Finally, there are instances where the relationship simply cannot give rise to a presumption and the weaker party must offer proof that an agreement was procured by undue influence.

It should be noted that these situations are different from cases concerning competence. The doctrine of undue influence does not question the person's ability to understand the choice that they made. Rather it looks at the issue of whether the decision was made freely, to the extent that it reflects the exercise of the person's autonomy.

\section{DOCTORS AND PROPERTY TRANSACTIONS}

In transactions involving property the relationships between medical practitioners and patients fall within the first category: undue influence is presumed and the onus is on the doctor to disprove it - i.e. to show that the conduct of the other party was 'the independent and well-understood act of a man in a position to exercise a free judgment based on information as full as that which was actually possessed'. ${ }^{2}$ Otherwise, the transaction will be set aside at law.

There are a few major ways in which this can be done. The single most important feature of the transaction that can assist the stronger party in trying to save it is the receipt by the applicant of external advice. If the individual acted after obtaining thorough independent advice, the courts will often be satisfied that he or she was free from any overwhelming influence.

If the stronger party can show that the weaker party did not suffer excessive loss, this increases the plausibility that the transaction was entered into freely. In instances where the applicant has made a gift this will, of course, always represent a deduction of their overall holdings, so the courts examine the relative extent of this in order to assess the gift's validity. ${ }^{3}$ In contractual dealings, if the court can see that the stronger party's contribution is adequate in relation to the benefit conferred by the weaker, this may help rebut the argument of undue influence.

Thus, so far as undue influence is a factor in the law of property, doctors need to understand that any contract made between the two, or gift given to the doctor by a patient, will be open to attack. The courts will automatically presume that the benefits were received as a 
result of the undue influence applied by the health professional and it will fall to the latter to show the contrary. Regarding gifts made to doctors by will there is no equivalent presumption; but, in view of the way the law regards the doctor-patient relationships, such wills are more vulnerable than most.

\section{THIRD PARTIES AND CONSENT TO MEDICAL TREATMENT}

The undue influence discussed so far is little concerned with the activities central to the doctor-patient relationshipnamely, the provision and acceptance of medical treatment. We now consider circumstances in which a patient's consent to or refusal of treatment may be vitiated by the influence of another person - a relative, a friend or even a healthcare practitioner. This type of undue influence is seen as separate from that involved in property transactions. Staughton LJ has said:

'The cases on undue influence in the law of property and contract are not, in my opinion, applicable to the different context of consent to medical or surgical treatment. The wife who guarantees her husband's debts, or the widower who leaves all his property to his housekeeper, are not in the same situation as a patient faced with the need for medical treatment.' ${ }^{4}$

The main reason for this divergence is that, in medical consent cases, the stronger party will not necessarily gain commercially from success in bringing influence to bear (except perhaps via the patient's will, if refusal of treatment leads to death). The case law demonstrates that patients tend to be pressured into refusing treatment by third parties holding two types of belief - religious beliefs, or beliefs in the superiority of alternative therapies. Suspicions may be aroused when the refusal is expressed under the influence of a third party in circumstances where the patient is weak or in great pain. The most commonly cited example is Re $T$ (Adult: Refusal of Medical Treatment). ${ }^{4}$ In this case a pregnant woman had been involved in a motor accident and was admitted to hospital after complaining of chest and shoulder pains. The patient had indicated on several occasions that she did not want a blood transfusion and signed a form of refusal. These refusals were alleged to have arisen in response to the influence of her mother, who was a practising Jehovah's Witness and present at times immediately before the patient had refused blood. The patient was not of that faith. After giving birth to a stillborn child the patient's condition worsened and she became unconscious. Her father and boyfriend sought judicial approval for the administration of blood products, and blood transfusions were authorized at trial on the basis that there was no binding refusal and that blood could be provided in her best interests.

On appeal, the Court of Appeal found that her refusals were invalid because of incapacity and also because they did not cover the extreme situation that had arisen. Additionally they would have been invalidated because of the undue influence of the mother.

In discussing undue influence Lord Donaldson MR stated that:

'A special problem arises if at the time the decision is made the patient has been subjected to the influence of some third party. This is by no means to say that the patient is not entitled to receive and indeed invite advice and assistance from others in reaching a decision, particularly from members of the family. But the doctors have to consider whether the decision is really that of the patient... The real question in each such case is, does the patient really mean what he says or is he merely saying it for a quiet life, to satisfy someone else or because the advice and persuasion to which he has been subjected is such that he can no longer think and decide for himself? In other words, is it a decision expressed in form only, not in reality? ${ }^{5}$

Lord Donaldson pointed to two main considerations when examining influences. The first is the strength of will of the patient. If the patient is in pain, depressed or tired or being treated with drugs, he or she is less likely to resist the influence of others. The second is the patient's relationship with the persuading party. A close family relationship heightens concern, especially in cases where religious beliefs are the reason for refusing treatment. The stronger the relationship the greater the ability of the persuader to override the decision-making process of the patient.

\section{MINORS}

Situations involving minors who are refusing treatment are exceptionally difficult, primarily because the law presumes that minors are incompetent unless they understand the nature and effects of treatment and the consequences of refusal. ${ }^{6}$ The complex combination of issues of competence and undue influence has led some judges to equate Gillickcompetency with the test of undue influence. The case of Re $S$ (A Minor) (Consent to Medical Treatment) ${ }^{7}$ is a good example. When $S$ refused to continue blood transfusions used to manage her thalassaemia, Justice Johnson, although stopping short of finding that her true wishes had been overborne by her Jehovah's Witness mother, did determine that $\mathrm{S}$ had been influenced through her sharing of that faith and her hope for a miracle. This led the judge to conclude that $\mathrm{S}$ did not fully appreciate the implications of her continued refusal 
of transfusions and that she was not 'Gillick-competent'. Similarly, in the Canadian decision of Re Dueck ${ }^{8}$ a 13-yearold boy was so misguided by his father as to the success rates of alternative remedies for his cancer that he was found to have been given no real choice but to accept the alternative treatment. The court simply decided that the level of influence prevented the boy being classed as a 'mature minor' capable of giving his own consent or refusal. The matter of influence having been dealt with in this way, in both cases the ability to accept treatment on behalf of the patient was vested in a local authority.

One downside of this merger is that it raises the bar of Gillick-competence to a far higher level than tests of competence for adults. For example in $\operatorname{Re} E$ (A Minor), ${ }^{9}$ a boy of 15 was judged incompetent not because of the presence of undue influence but because his will had been conditioned by his faith and the judge was unable to say that the child was acting with free will. Nor was the judge certain that the child would not later change his religious convictions. The practical effect of the decision is to allow a judge to ignore a minor's refusal if he or she disagrees with the minor's religious convictions. Realistically, there may be good reasons for ignoring minors' refusals of treatment, but judges should not manipulate the Gillick test or the doctrine of undue influence to achieve such a result. ${ }^{10}$

\section{CONSENT AND THE DOCTOR-PATIENT RELATIONSHIP}

A recent decision has raised the possibility that traditional undue-influence concepts will acquire greater significance in the law of consent. The essential facts of Mrs $U_{v}$ Centre for Reproductive Medicine are as follows. $\mathrm{Mr}$ and Mrs $\mathrm{U}$ were attempting to overcome the effects of his earlier vasectomy so as to enable them to produce a child. The means adopted was surgical retrieval of his sperm which was then to be used in an IVF procedure involving Mrs U. Before the process was started, Mr U completed two consent forms. One was that of the centre itself, relating to storage and disposal of sperm, which contained a statement that it was the 'ethical policy of this unit not to perform posthumous insemination'. The other form was that required by the Human Fertilisation and Embryology Act 1990 which Mr U completed by choosing to authorize, in the event of his death, the continued storage of his sperm for use in an IVF procedure by his wife.

On 25 October 2000, subsequent to the extraction of his sperm, Mr U and his wife had a treatment planning meeting with Ms Hinks, a specialist nursing sister at the centre, at which the consent form was altered by Mr U so as to allow his sperm to perish in the event of his death and withdrawing his consent to their continued storage for the purpose of fertilization. The couple then progressed with the IVF programme, which was unsuccessful in establishing a pregnancy. Before they could try again, Mr U died unexpectedly.

The centre brought proceedings seeking clarification as to what it should do with Mr U's sperm. In light of his amendments to the consent form, it was an offence under s.41(2) of the Act for the centre to continue storing Mr U's gametes. But it was acknowledged that Mrs U might have an interest in their disposal. Mrs U responded to the action by arguing that the centre should continue to store the sperm so as to allow her to proceed with the IVF programme. Her basis for this was that her husband's initial consent to this course of action had not been validly retracted by the amendments made on 25 October since those were tainted by the undue influence of Ms Hinks.

It was not disputed that Ms Hinks, who personally subscribed to the centre's policy against facilitating posthumous birth, had asked $\mathrm{Mr} \mathrm{U}$ to change the form and revoke his earlier given consent. Mrs U argued that her husband had complied being under the impression that treatment would stop if he did not amend the consent form - a view that was largely favoured by the President of the Family Division of the High Court of Justice at first instance. But was undue influence present so as to vitiate Mr U's amendments of 25 October?

The President considered the opinions delivered in $\operatorname{Re} T$ and concluded that:

‘. . it is difficult to say that an able, intelligent, educated man of 47 , with a responsible job and in good health, could have his will overborne so that the act of altering the form and initialling the alterations was done in circumstances in which $\mathrm{Mr} U$ no longer thought and decided for himself . . . He succumbed to the firmly expressed request of $\mathrm{Ms}$ Hinks and under some pressure. But to prove undue influence, $\mathrm{Mr} \mathrm{U}$ has to show something more than pressure.' 12

On appeal, Mrs U submitted that the President had set the test for undue influence too high and the question should simply be whether Mr U had had a real choice to refuse to alter the consent form. The Court of Appeal rejected both this argument and any suggestion that $\mathrm{Ms}$ Hinks' conduct amounted to undue influence upon Mr U's free will. Curiously, in doing so, it purported to distinguish this situation from all other incidents of undue influence recognized at law, yet endorsed the President's test which was clearly derived in part from the context of refusal of treatment in $\operatorname{Re} T$ and the standard of undue influence generally at law. The key passages of the decision are these:

'In this context, none of the case law on undue influence in other contexts is particularly helpful. This is not like 
deciding upon the validity or enforcement of a will, gift or other transaction, which may have been procured by the undue influence of the person who will benefit from it. The Centre did not stand to benefit from the withdrawal of consent. Nor is it like deciding upon the lawfulness of medical treatment. There are other justifications for performing life-saving medical treatment apart from the possession of an effective consent. There is no justification for continuing to store human sperm. Hence a Centre having in their possession a form [of consent] should be both entitled and expected to rely upon that form according to its letter, unless and until it can clearly be established that the form does not represent a valid decision by the person apparently signing it. The most obvious examples are forgery, duress, or mistake as to the nature of the form being signed. The equitable concepts of misrepresentation and undue influence may have a part to play but the courts should be slow to find them established in such a way as to supply a centre with a consent which they would not otherwise have.'12

\section{CONCLUSION}

The facts of Mrs $U$ present us with a novel context for the operation of broad notions of undue influence. Just as in respect of undue influence affecting a patient's refusal of medical treatment, there is no direct benefit to the centre akin to that required to vitiate property dealings. But while that distinction is obvious, it does not seem of much import because the courts nevertheless remain receptive to arguments of undue influence in the medical cases. Moreover, as the Court of Appeal makes clear in upholding the President's handling of Mrs U, the test for undue influence is essentially the same across the board, property or otherwise — the weaker party's will must have been so overborne as to prevent its independent exercise. However, the absence of a 'benefit' requirement in respect of medical service cases, whilst only sensible, does logically mean that there are actually fewer obstacles for the applicant seeking to make out undue influence in those cases.

Does this matter? In cases such as Re $T$, the answer must surely be no. Where a patient is refusing essential treatment because of the hold others have over him or her, then an ability for doctors and health authorities to reappraise the binding nature of the patient's expressed wishes in light of the undue influence is clearly desirable. Why Mrs $U$ is both different and important is that it concerns the influence emanating not from a third party but from the health professional directly. The Court of Appeal's reluctance to extend the equitable rules traditionally governing property transactions is understandable. But in acknowledging that they 'may have a part to play', the Court presents the possibility that patients may subsequently claim that their consent to or refusal of treatment was unduly influenced by a doctor. Although Mrs $U$ maintains the strict test as to what that influence must amount to, it is not difficult to imagine that in many medical cases a weakened patient simply trusts the doctor's opinion and accedes to what is recommended.

Although the findings in Mrs $U$ seem to foreclose the possibility that undue influence will acquire any immediate significance in the law of consent and the liability of doctors for treatment, they do not entirely dismiss the extension of the concept into that domain. And, if anything, the advancement of arguments of undue influence in cases of medical treatment, such as those in $\operatorname{Re} T$ and Mrs $U$, indicates that new applications of existing legal principles will continue to emerge.

\section{REFERENCES}

1 Barclays Bank plc v O'Brien [1994] 1 AC 180 at 189-190; Royal Bank of Scotland v Etridge (No 2) [2002] 2 AC 773

2 Johnson v Buttress [1936] 56 CLR 113 at 134

3 Union Fidelity Trustee Co v Gibson [1971] VR 573

4 Re T (Adult: Refusal of Treatment) [1992] 4 All ER 649 at 669

5 [1992] 4 All ER at 662

6 Gillick v West Norfolk and Wisbeck Area Health Authority [1986] AC 112

7 [1995] Fam 20

$8 \quad 171$ DLR (4th) 761 [1999]

9 [1993] 1 FLR 386

10 See BH v Alberta (Director of Child Welfare) [2002] ABQB 371 at [36]; upheld on appeal in $H(B)$ v Alberta (Director of Child Welfare) [2002] ABCA 109

11 [2002] EWCA Civ (24 April 2002)

12 Centre for Reproductive Medicine $v$ Mrs $U$ (unreported, High Court of Justice, Family Division, The President, 25 January 2002) at para 28 